\title{
Fitz-Hugh-Curtis Syndrome-like Findings: Chemical Stimulation by the Contrast Agent
}

\author{
Kazuhiko Morii, Takeharu Yamamoto, Hiroshi Kishida and Hiroaki Okushin
}

Key words: Fitz-Hugh-Curtis syndrome, iodized oil, hysterosalpingography

(Intern Med 52: 2587-2588, 2013)

(DOI: 10.2169/internalmedicine.52.1173)

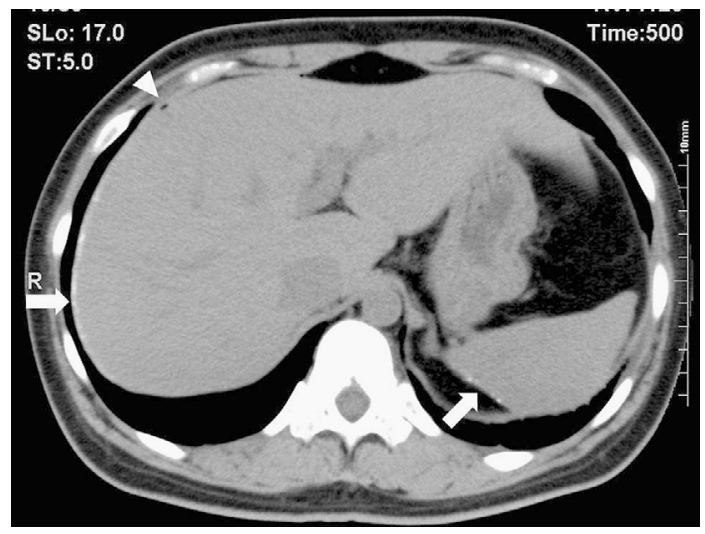

Picture 1.

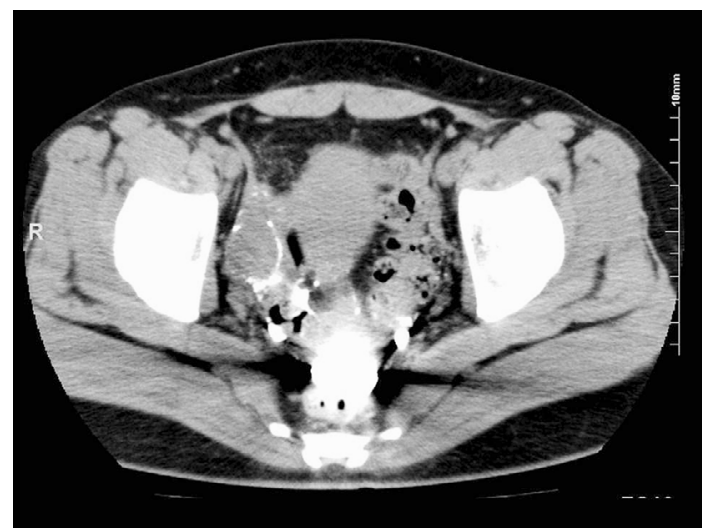

Picture 3.

A 37-year-old woman was referred to our hospital because of right upper quadrant abdominal pain. Her body temperature was $36.4^{\circ} \mathrm{C}$. Her white cell count was $6,000 /$ $\mathrm{mm}^{3}$ and her serum c-reactive protein level was $0.09 \mathrm{mg} / \mathrm{dL}$. Two days earlier, she had undergone a hysterosalpingography with iodized oil at another obstetric clinic for the inves-

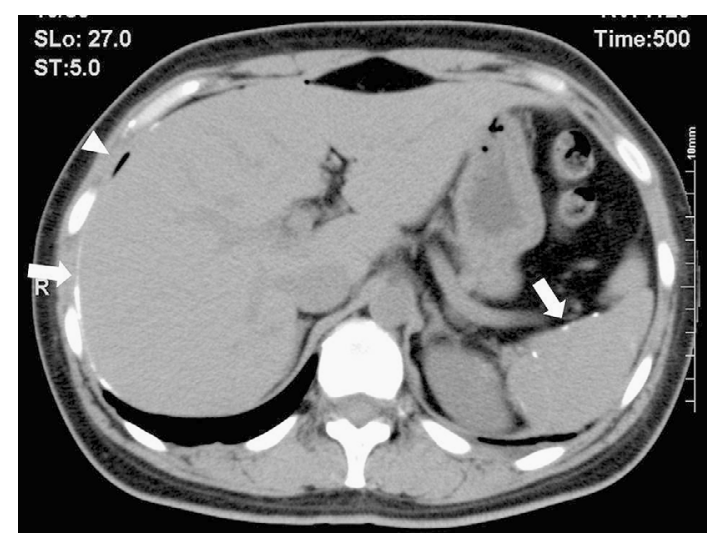

Picture 2.

tigation of infertility. Iodized oil, which is an X-ray contrast medium originally developed for lymphography, is sometimes used for the purpose of hysterosalpingography (1). Abdominal computed tomography without administration of contrast material showed a thin high-density layer of iodized oil on the surface of the liver and spleen (arrows), with intra-abdominal free air (arrow heads) (Picture 1, 2). There were dense deposits of iodized oil in the uterus and pelvic cavity (Picture 3). The pathophysiology of the patient was consistent with Fitz-Hugh-Curtis syndrome. Fitz-HughCurtis syndrome is a hepatic capsulitis usually resulting from a direct spread of pelvic organ infections. However, the paucity of acute inflammatory findings favored that the iodized oil was the possible cause of chemical irritation, rather than infectious processes (2). The symptoms disappeared after the administration of antibiotics and nonsteroidal anti-inflammatory drugs.

The authors state that they have no Conflict of Interest (COI). 
Intern Med 52: 2587-2588, 2013 DOI: 10.2169/internalmedicine.52.1173

\section{References}

1. Lindequist S, Justesen P, Larsen C, Rasmussen F. Diagnostic quality and complications of hysterosalpingography: oil- versus watersoluble contrast media- a randomized prospective study. Radiol- ogy 179: 69-74, 1991.

2. Eisenberg AD, Winfield AC, Page DL, Holburn GE, Schifter T, Segars JH. Peritoneal reaction resulting from iodinated contrast material: comparative study. Radiology 172: 149-151, 1989.

(C) 2013 The Japanese Society of Internal Medicine http://www.naika.or.jp/imonline/index.html 